\title{
Syndecan-I Shedding by Matrix Metalloproteinase-9 Signaling Regulates Alveolar Epithelial Tight Junction in Lipopolysaccharide-Induced Early Acute Lung
} Injury

\author{
Dong Zhang' \\ Jin-tao Zhang ${ }^{\prime}$ \\ Yun Pan' \\ Xiao-fei Liu' \\ Jia-wei $\mathrm{Xu}\left(\mathbb{D}^{2}\right.$ \\ Wen-jing Cui ${ }^{1}$ \\ Xin-rui Qiao' \\ Liang Dong ${ }^{1,2}$
}

'Department of Respiratory, Shandong Qianfoshan Hospital, Cheeloo College of Medicine, Shandong University, Jinan, People's Republic of China; ${ }^{2}$ Department of Respiratory, Shandong Provincial Qianfoshan Hospital, Shandong University, The First Affiliated Hospital of Shandong First Medical University, Shandong Institute of Respiratory Diseases, Jinan, People's Republic of China
Correspondence: Liang Dong Department of Respiratory, Shandong Provincial Qianfoshan Hospital Shandong University, The First Affiliated Hospital of Shandong First Medical University, Shandong Institute of Respiratory Diseases, Jinan, People's Republic of China Email d15506@I26.com
Introduction: Alveolar epithelial tight junction damage and glycocalyx syndecan-1 (SDC1) degrading are key factors to pulmonary edema of acute lung injury (ALI). Matrix metalloproteinase-9 (MMP-9) was involved in glycocalyx shedding, which was vital in SDC-1 degrading. This study aimed to investigate the effects of MMP-9-mediated SDC-1 shedding on tight junction in LPS-induced ALI.

Methods: Mice were intratracheally atomized with $5 \mathrm{mg} / \mathrm{kg}$ LPS to stimulate different periods and LPS stimulation for 6 hours for further studies. A549 cells was stimulated for 6 hours by active MMP-9 protein to assess the effects of active MMP-9 protein on SDC-1 and tight junction. Afterward, the mice treated with MMP-9 shRNA or A549 cells were treated with MMP-9 siRNA before LPS stimulation for 6 hours to explore the effects on glycocalyx SDC-1 and tight junction. Moreover, the mice were treated with recombinant SDC-1 protein or A549 cells were over-expressed by pc-SDC-1 before LPS stimulation for 6 hours to explore the effects of SDC-1 on tight junction.

Results: The mice persistent exposure to LPS showed that MMP-9 expression, glycocalyx SDC-1 shedding (SDC-1 decreased in alveolar epithelium and increased in the BALF), tight junction impairment, FITC-albumin infiltration, and other phenomena began to appear after 6 hours of LPS treatment in this study. The levels of SDC-1 and tight junction significantly decreased by active MMP-9 protein stimulation for 6 hours in the A549 cells. Therefore, LPS stimulation for six hours was selected for investigating the underlying effects of MMP9-mediated SDC-1 shedding on the alveolar epithelial tight junction and pulmonary edema. Further vivo analysis showed that down regulation MMP-9 expression by MMP-9 shRNA significantly alleviated glycocalyx SDC-1 shedding (SDC-1 increased in alveolar epithelium and decreased in the BALF), tight junction (occludin and ZO-1) damage, and FITC-albumin infiltration in LPS-induced early ALI mice. The vitro results also showed that MMP-9 siRNA alleviated glycocalyx SDC-1 shedding (SDC-1 increased in cell culture medium and decreased in cell surface) and tight junction damage by downregulating MMP-9 expression in LPSstimulated A549 cells. In addition, pretreatment with recombinant mouse SDC-1 protein significantly alleviated glycocalyx (SDC-1 increased in alveolar epithelium) and tight junction damage, and FITC-albumin infiltration in LPS-induced early ALI mice. Overexpression SDC-1 by pc-SDC-1 also significantly decreased tight junction damage in LPS-stimulated A549 cells. Conclusion: Glycocalyx SDC-1 shedding mediated by MMP-9 significantly aggravated tight junction damage, which further increased the pulmonary edema.

Keywords: glycocalyx, SDC-1, MMP-9, tight junction, early ALI 


\section{Graphical Abstract}

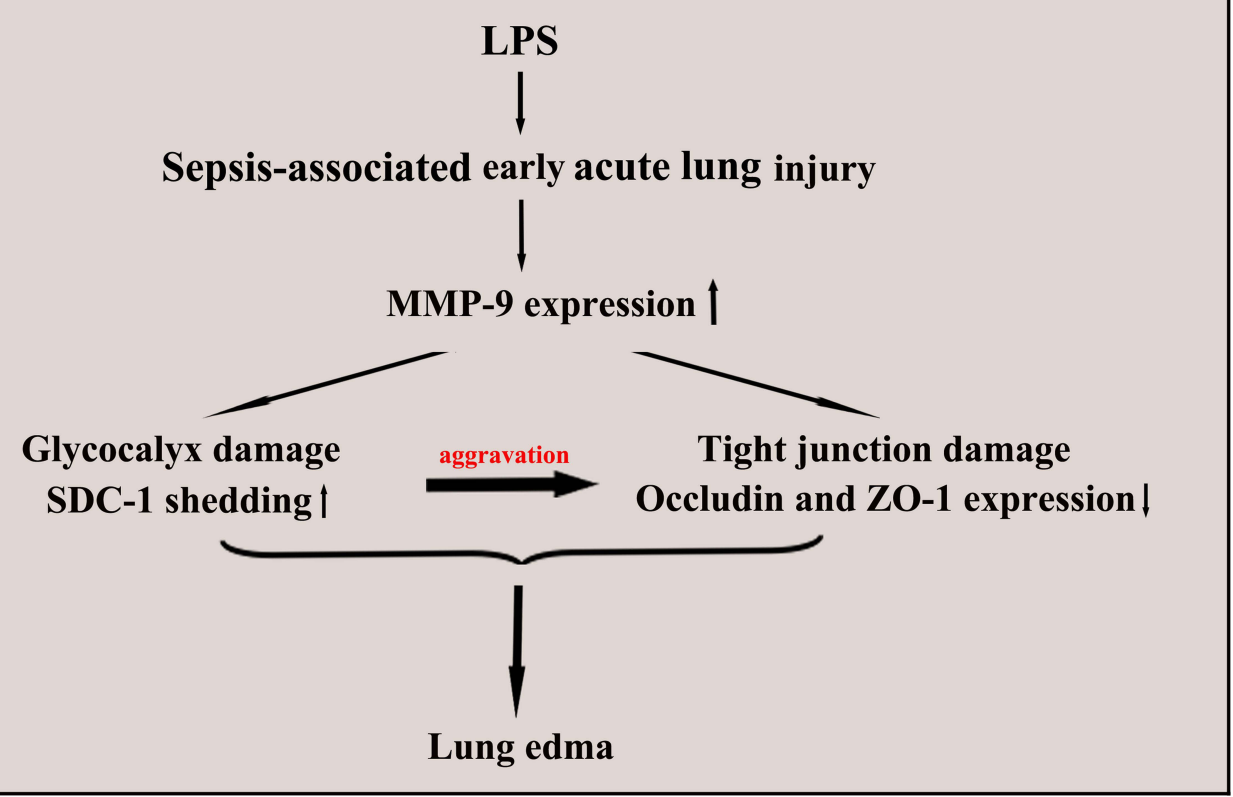

\section{Background}

Acute pulmonary injury is characterized by acute and persistent pulmonary inflammatory response syndrome. Several pathogenic factors of acute pulmonary injury exist, of which sepsis is one of the main factors for increased epithelial barrier damage. ${ }^{1}$ With in-depth understanding of pathogenesis, scholars recognized that the epithelium is not only an important barrier but also a damaged target, which has a significant effect on the development of acute pulmonary injury. ${ }^{2,3}$

The glycocalyx and junctions of the alveolar epithelium play an important protective role in the acute pulmonary injury. The glycocalyx, a layer of negatively charged complex glycoproteins, serves a pivotal role in physiological processes, including alveolar permeability and inflammatory response. ${ }^{4,5}$ The glycocalyx is composed of syndecan-1 (SDC-1), heparan sulfate (HS), hyaluronic acid, and chondroitin sulfate, where SDC-1 accounts for the largest amount. ${ }^{4,6}$ SDC-1 is susceptible to variety of factors, such as the matrix metalloproteinase-9 (MMP-9), which is an SDC1-degrading key factor. ${ }^{7}$ The degradation and shedding of SDC-1 may indicate disease aggravation. A new uncovered research reported that SDC-1 is involved in the formation of pulmonary fibrosis induced by bleomycin. ${ }^{8}$

Tight junction is widely found in pulmonary epithelial cells and plays an important role in maintaining the mechanical barrier of epithelia. Occludin and zonula occludens protein-1 (ZO-1) are key components of tight junctions, which play a vital role in permeability and inflammatory response. ${ }^{9,10}$ Adhesion and gap junction-mediated intercell signaling is also significant for paracellular transport permeability between epithelial cells. Gap junction protein 43 (connexin 43, Cx43) and adherens junction protein e-cadherin are widely expressed in pulmonary epithelial cells. ${ }^{11,12}$ Mensah et al demonstrated that HS degradation in the glycocalyx disrupts $\mathrm{Cx} 43$, whereas regeneration of HS restores interendothelial communication. ${ }^{13}$ However, whether SDC-1 shedding is a vital player in tight junction damage during acute pulmonary injury remains to be elucidated.

Lipopolysaccharide (LPS) is a cell wall component of gram-negative bacteria and an important pathogen causing acute pulmonary injury. ${ }^{14,15}$ In the present study, the dynamic changes of the glycocalyx, SDC-1, occludin, and ZO-1 in ALI mice induced by LPS and 
the potential mechanisms of SDC-1 on tight junction were analyzed. This study broadens our understanding of the epithelium and provides a new theoretical basis for the prevention and treatment of ALI.

\section{Methods \\ Materials}

Diamidine phenylindole (DAPI) and LPS (Escherichia coli O55:B5) were obtained from Sigma-Aldrich Biotechnology Ltd. Rabbit monoclonal antibodies MMP-9 (ab38898), occludin (ab216327), e-cadherin (ab51034), ZO-1 (ab216880), vimentin (ab92547), $\alpha$ SMA (ab124964), albumin (ad207327), and active MMP-9 protein (ab168863) were attained from Abcam Biotechnology Ltd. Human and mouse samples of SDC-1 ELISA were bought from Zcibio Biotechnology Ltd (ZC54317, ZC-37836). Recombinant mouse SDC-1 protein was from RD Biotechnology Ltd. Rabbit monoclonal antibodies GAPDH (ET1601-4), Ly-6G (0809-11), and SDC-1 (ET1703-42) were purchased from Huaan Biotechnology Ltd. HRP-conjugated goat anti-rabbit IgG, Alexa Fluor 488, and 549 goat anti-rabbit IgG were purchased from Bioss Biotechnology Ltd. Sodium cacodylate buffer and lanthanum nitrate were obtained from Zhongjing Instrument Co., Ltd. The human MMP9 siRNA was constructed by Gene Pharma Biotechnology.

\section{Lentivirus Construction}

The mouse MMP-9 small hairpin RNA (shRNA) lentivirus was constructed by Gene Pharma Biotechnology. Oligonucleotides encoding in the mice MMP-9 shRNA targeting sequences 5'-GCGCTCTGCATTTCTTCAAGG $-3^{\prime}$. The efficiency of the knockdown MMP-9 was established by measuring MMP-9 protein level.

\section{Animals Studies}

Male C57BL/6 mice, aged 7-8 weeks and weighed 18-20 g, were purchased from Jinan Animal Feed Center (Shandong, China). Animal care and laboratory procedures were approved by Shandong University. Chinese guidelines for the welfare of laboratory animals (GB/T 35823-2018), which was published by the standardization administration of China, was followed in this study.

The mice were randomly divided into control and LPS (stimulation for $6,12,18$, and $24 \mathrm{~h}$ ) groups $(\mathrm{n}=8 /$ group) to observe the dynamic changes in various indicators. The mice in the LPS group were intratracheally atomized with $5 \mathrm{mg} / \mathrm{kg}$ LPS to stimulate different periods. ${ }^{16}$ The mice in the control group were intratracheally atomized with the same amount of normal saline. Mouse lung and bronchoalveolar lavage fluid (BALF) was collected after the mice were anesthetized with sodium pentobarbital. The mice were euthanized with carbon dioxide (100\%) in a closed device and wellventilated environment.

Thereafter, the mice were randomly divided to control, LPS, MMP-9 shRNA+LPS, and LV2-NC groups $(n=8 /$ group). The mice in the control group intratracheally atomized the same amount of normal saline for the same amount of time to stimulate for 6 hours. The mice in the LPS group were intratracheally atomized with $5 \mathrm{mg} / \mathrm{kg}$ LPS to stimulate for 6 hours. The mice in MMP-9 shRNA+LPS group were injected by tail vein with a total 2U MMP-9 shRNA (2U/interval three days, $2 \times 10 * 8 / \mathrm{U} /$ each time), and then exposed to LPS for stimulation of 6 hours LPS after the last injection of MMP-9 shRNA intervention for 3 days. The mice in LV2-NC group received the same number of doses as the MMP-9 shRNA+LPS group. Afterward, the lung samples were collected after the mice were anesthetized with sodium pentobarbital. The mice were euthanized with carbon dioxide $(100 \%)$ in a closed device and well-ventilated environment.

In addition, the mice were randomly divided to control, LPS, recombinant SDC-1+LPS, and recombinant SDC-1 groups ( $\mathrm{n}=8$ /group) for further study of SDC-1 on tight junction. The mice in the recombinant SDC-1+LPS group were intratracheally atomized with $500 \mathrm{ng}$ /day recombinant SDC-1 protein for 7 days and then exposed to LPS to stimulate for 6 hours. The mice in the recombinant SDC-1 group intratracheally atomized with the same amount of recombinant SDC-1 protein for the same amount of time.

At last, the mice were intratracheally atomized with $5 \mathrm{mg} / \mathrm{kg}$ LPS to stimulate for 28 days to observe the dynamic changes in inflammation and remodeling.

\section{Cell Studies}

The A549 cells were purchased from the Shanghai cell bank and cultured in $95 \%$ air, $5 \% \mathrm{CO}_{2}$, and a $37{ }^{\circ} \mathrm{C}$ incubator in complete medium (Dulbecco's modified Eagle's medium supplemented with $10 \%$ fetal bovine serum $[\mathrm{FBS}])$.

The A549 cells were divided into control and active MMP-9 groups to assess the effects of MMP-9 on SDC-1 
and tight junction. In the control group, A549 cells were cultured without any intervention in the medium. Whereas in the active MMP-9 group, A549 cells were cultured with active human MMP-9 $(0.8 \mu \mathrm{g} / \mathrm{mL})$ in the medium.

Hence, A549 cells were divided to control, LPS, MMP-9 siRNA+LPS, and NC siRNA groups. The A549 cells in the control group were cultured without any intervention in medium. The A549 cells in the NC siRNA group were transfected with no known target siRNA. The A549 cells in the LPS group were cultured with LPS $(100 \mathrm{ng} / \mathrm{mL})$ in medium. The A549 cells in the MMP-9 siRNA+LPS group were plated in six-well plates at $50-70 \%$ confluence using 40 nM MMP-9 siRNA and Lipofectamine 2000 (Invitrogen) according to the manufacturer's instructions. Six hours after transfection, wells were supplemented with a medium containing 1\% FBS for 48 hours, and then washed with PBS and added with LPS $(100 \mathrm{ng} / \mathrm{mL})$ for stimulation of 6 hours. The effect of MMP-9 siRNA in silencing MMP-9 protein expression was used for further studies. The MMP-9 siRNA and negative siRNA (NC siRNA) sequences were as follow: MM-9 siRNA: sense 5'-CUA UGG UCC UCG CCC UGA ATT-3', and anti-sense 5'-UUC AGG GCG AGG ACC AUA GAG-3'; NC siRNA: sense 5'-UUC UCC GAA CGU GUC ACG UdTdT-3', and anti-sense 5'-ACG UGA CAC GUU CGG AGA AdTdT-3'.

For further analysis, the integrated length of SDC-1 was inserted into the control vector (pc-DNA3.1, Gene Pharma Biotechnology, China), and identified as pcSDC-1. The A549 cells were divided to control, LPS, pc-SDC-1+LPS, and pcDNA3.1 groups. The control group consists of the A549 cells without intervention. The LPS group comprises A549 cells were cultured with LPS $(100 \mathrm{ng} / \mathrm{mL})$. The A549 cells in the pc-DNA3.1 group were transfected with lipofectamine 3000 reagent and pc-DNA3.1 $(1 \mu \mathrm{g} / \mathrm{mL})$. The pc-SDC-1+LPS group include the lipofectamine 3000 reagent and pc-SDC-1 $(1 \mu \mathrm{g} / \mathrm{mL})$ which were employed for A549 cells transfection. Forty-eight hours after transfection, the A549 cells were cultured with LPS $(100 \mathrm{ng} / \mathrm{mL})$ stimulation for 6 hours, and the A549 cells were harvested for further studies.

\section{Histopathology}

The lungs of mice were fixed and dehydrated by $4 \%$ paraformaldehyde, embedded in paraffin, cut into 5 $\mu \mathrm{m}$-thick specimens, and stained with hematoxylin and eosin (HE). Eight high-power regions were randomly selected from each sample, and the obtained mean was the pathological score of each sample in accordance with the lung injury score criteria. ${ }^{16,17}$

\section{Pulmonary Ultrastructure}

First, the mice were perfused with 2\% glutaraldehyde, 2\% sucrose, $0.1 \mathrm{M}$ sodium diarsenate buffer ( $\mathrm{pH} 7.3$ ), and 2\% lanthanum nitrate through the right ventricle after the application of anesthesia with sodium pentobarbital. ${ }^{18}$ Second, the lung tissue was then removed in a fixative and washed with sodium dimethacharsenate buffer. The solution containing 2\% osmium tetroxide and $2 \%$ lanthanum nitrate was embedded in aragonite. Finally, the microstructure was sectioned and observed by using an electron microscope.

\section{Immunofluorescence}

The cells were inoculated on 24 well plates to detect the contents of MMP-9, SDC-1, ZO-1, and occludin in A549 cells. After conducting different pretreatments and treatments, the cells were incubated with MMP-9, SDC-1, ZO-1, and occludin antibodies. Afterward, the fluorescence secondary antibody and DAPI staining were added to obtain images by using a fluorescence microscope.

To detect the contents of albumin, SDC-1, occludin, MMP-9, and ZO-1 in lungs, the lung samples were sealed with goat serum after dewaxing and antigen repair, incubated with different antibodies, washed with PBS, and stained with fluorescence secondary antibody and DAPI. The images were obtained using a fluorescence microscope.

\section{Immunohistochemistry}

Lung sections were dewaxed and dehydrated. After antigen repair and removal of endogenous peroxidase, lung sections were incubated with SDC-1 and occludin antibodies (including 5\% goat serum) at room temperature for 6 hours. After washing the lung sections with PBS, the second antibody was added to the sections, which were incubated in a dark cage for 30 minutes. The DAB solution was added to the sections and incubated after being washed with PBS. Thereafter, the lung sections were washed with water, restrained, dehydrated, sealed, and photographed under a microscope.

\section{Western Blotting}

Lung tissue proteins were isolated and extracted in accordance with the requirements of the protein extraction kit (Beyotime Biotechnology, China). The protein concentration was determined using a BCA kit (Beyotime Biotechnology, China). The proteins were separated by sodium dodecyl sulfate-polyacrylamide gel electrophoresis and transferred 
to a polyvinylidene fluoride (PVDF) membrane. The PVDF membrane was incubated with primary antibodies (Ly-6G, MMP-9, SDC-1, ZO-1, e-cadherin, occludin, vimentin, $\alpha$ SMA, and GAPDH antibodies) at $4{ }^{\circ} \mathrm{C}$ for 12 hours. The goat anti-rabbit antibody was coincubated with the PVDF membrane for 80 minutes. Finally, the gray value of the protein was revealed by staining the PVDF membrane with enhanced chemiluminescence reagent.

\section{Level of TNF- $\alpha$, IL-I $\beta$, and IL-6 in the BALF} BALF came from the intratracheal injection of $500 \mu \mathrm{L}$ PBS per a mouse for four times. The BALF and serum supernatant were collected by centrifuging at $3500 \mathrm{rpm}$ under $4{ }^{\circ} \mathrm{C}$ for 20 minutes. The level of TNF- $\alpha$ (70-EK282/4, Multisciences), IL-1 $\beta$ (Beyotime, China), and IL-6 (70-EK206/3, Multisciences) in the BALF was measured by ELISA.

\section{Soluble SDC-I Levels in the BALF and Cell Culture Medium}

After conducting different treatments and pretreatments of mice and cells, BALF and cell culture medium were collected, and supernatant of each sample was collected after $3500 \mathrm{rpm}$ under $4{ }^{\circ} \mathrm{C}$ for $20 \mathrm{~min}$. Thus, the supernatant was measured by SDC-1 ELISA (Zcibio Biotechnology, China).

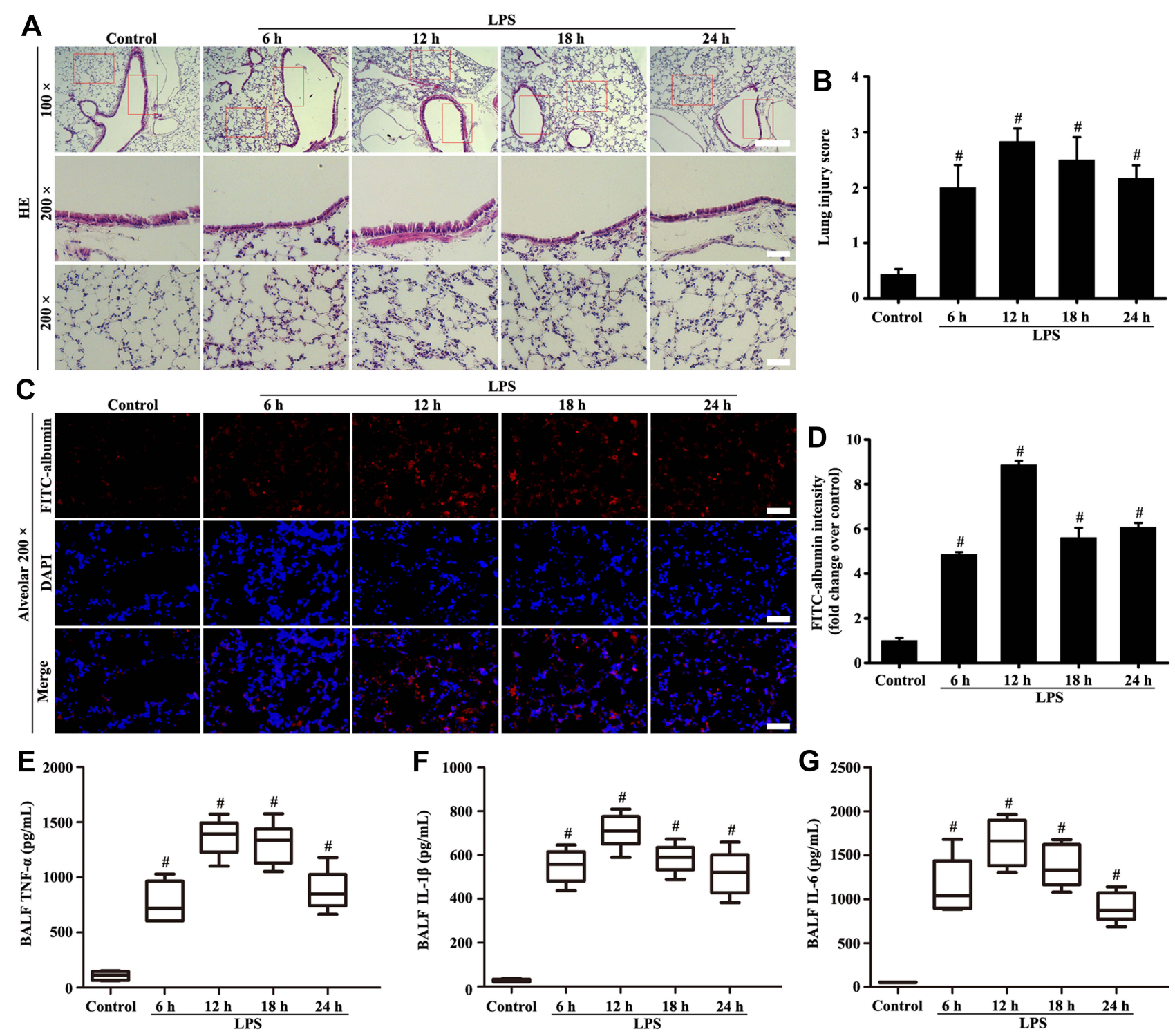

Figure I Mice were intratracheally atomized with $5 \mathrm{mg} / \mathrm{kg}$ LPS (stimulation for 6, 12, 18, and $24 \mathrm{~h}$ ) to observe pathological changes. Histological evaluation of lung was conducted by HE staining (A, magnification, $\times 100$; scale bar, $100 \mu \mathrm{m}$. Magnification, $\times 200$; scale bar, $50 \mu \mathrm{m}$ ). FITC-albumin permeability was determined by Fluorescence analysis (C, magnification, $\times 200$; scale bar, $50 \mu \mathrm{m})$. Inflammatory cytokine of TNF- $\alpha(\mathbf{E})$, IL-I $\beta$ (F), and IL-6 (G) in the BALF were measured by ELISA kits. (B) Lung injury score of (A). (D) Fluorescence intensity analysis of (C). All data are presented as the mean \pm SD of three independent experiments. ${ }^{\#} p<0.05$ vs the control group. 


\section{Statistical Analysis}

The data are presented as the mean \pm standard deviation (SD). Two groups were evaluated by a student's $t$-test. Comparisons among multiple groups were performed using one-way and two-way ANOVA analyses. $\mathrm{p}<0.05$ was considered statistically significant. All statistical analyses were performed using SPSS 17.0 (IBM Corp.).

\section{Results}

Pathological and Inflammatory Damage of Lung Began to Worsen at the Sixth Hour of LPS Treatment

Figure $1 \mathrm{~A}-\mathrm{G}$ shows that the alveolar structure of lung was intact, and almost no inflammatory cell and FITC-albumin infiltration occurred in the control group. However, the

A

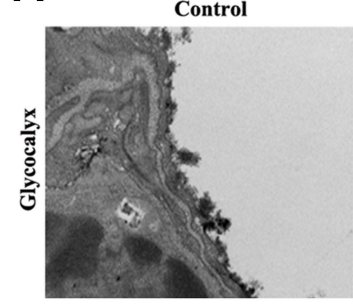

B

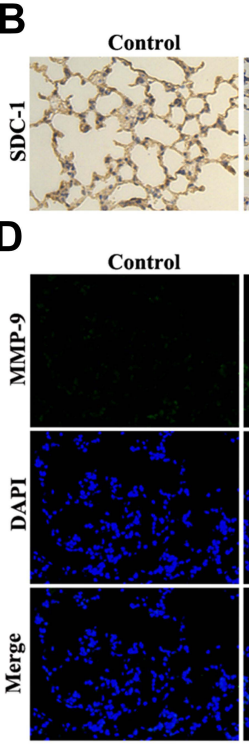

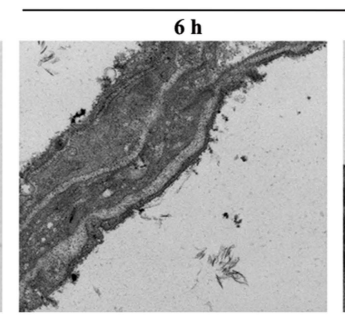

LPS
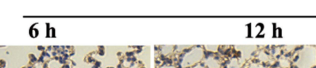
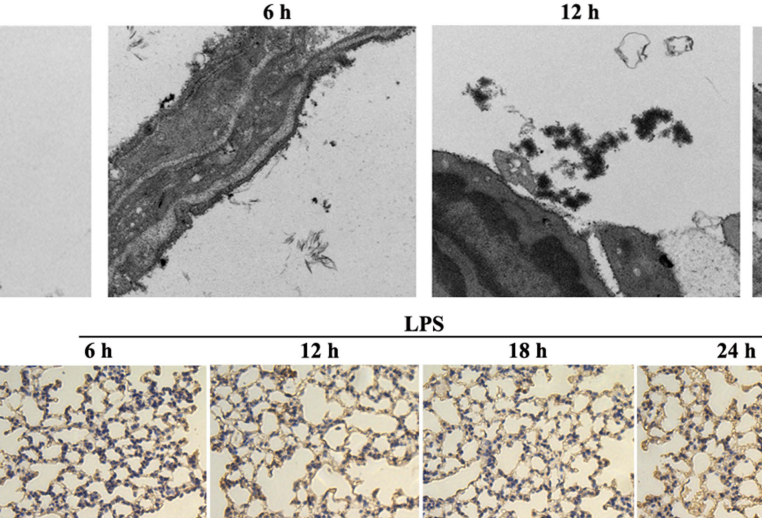

LPS
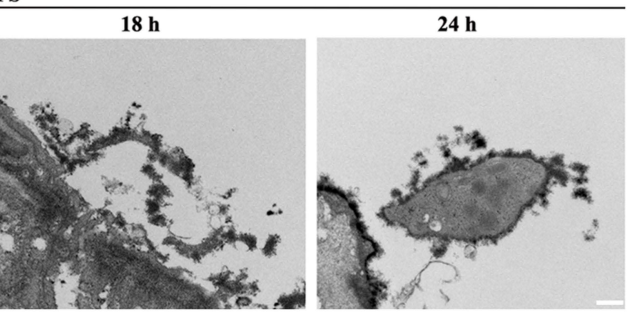

C

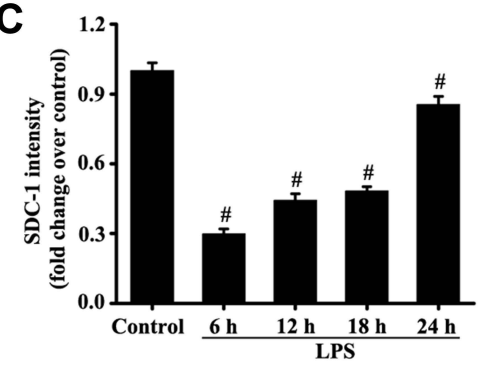

E
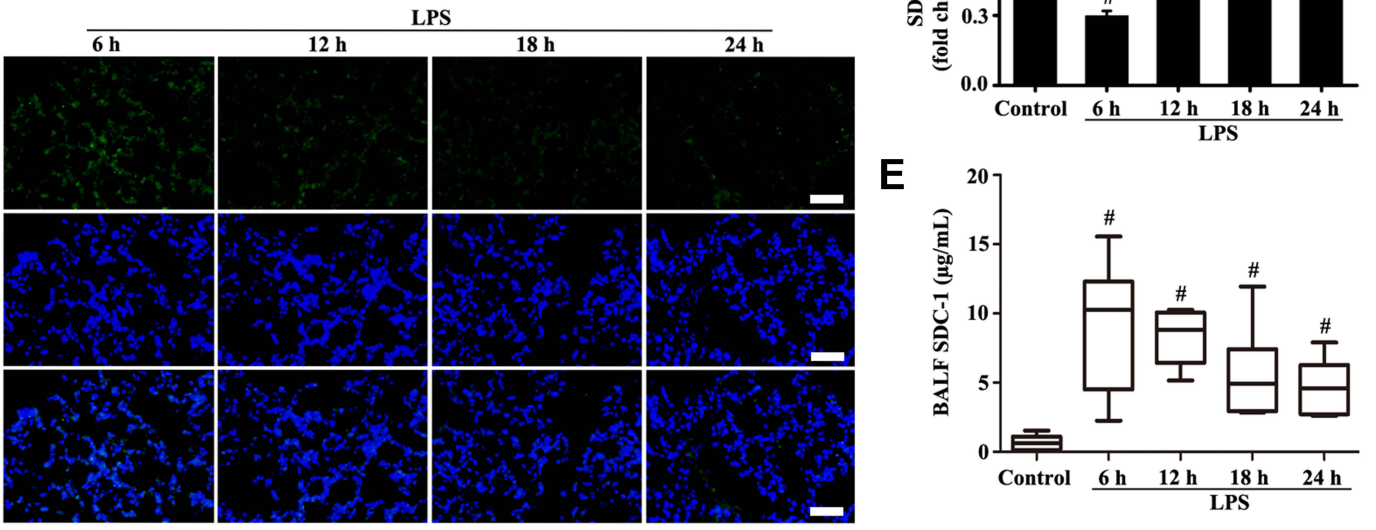

LPS
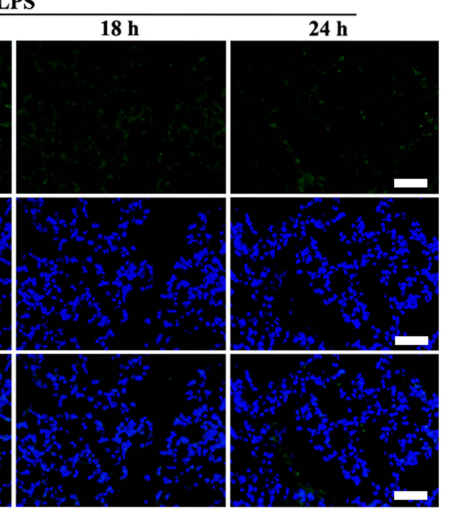
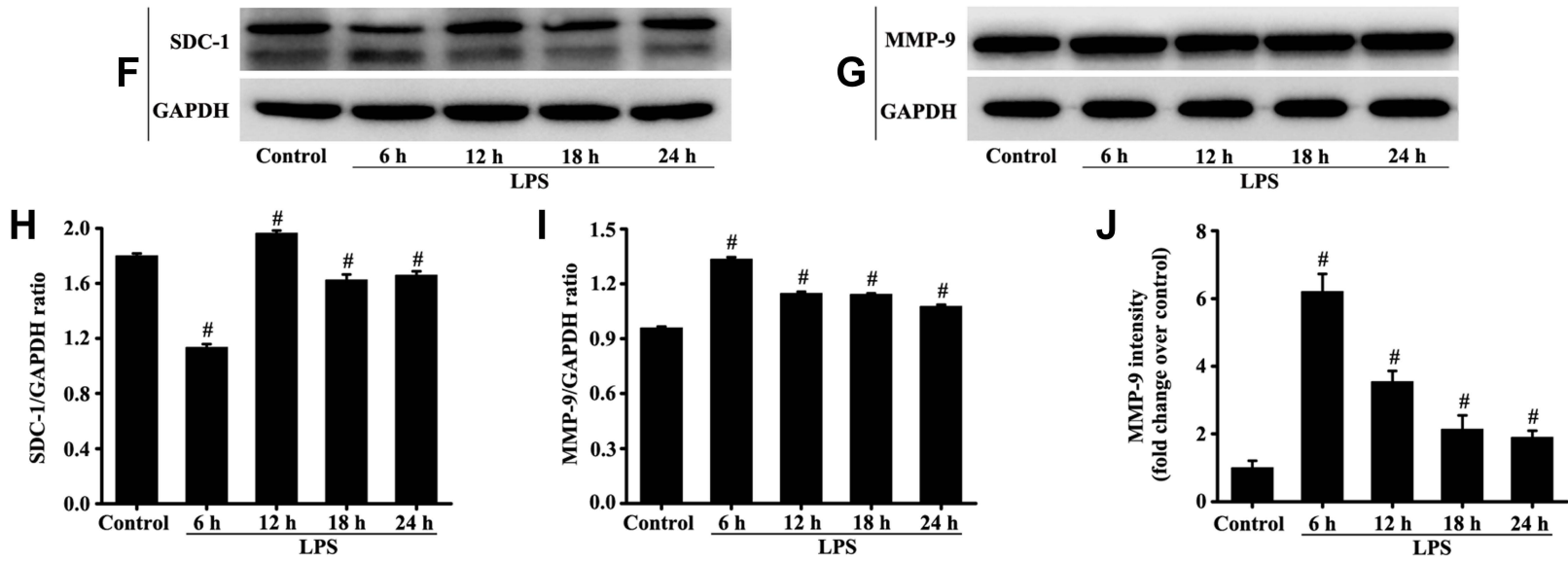

Figure 2 Mice were intratracheally atomized with $5 \mathrm{mg} / \mathrm{kg}$ LPS (stimulation for 6, 12, 18, and $24 \mathrm{~h}$ ) to observe the changes of glycocalyx and MMP-9. Glycocalyx was analyzed by an electron microscope $(\mathbf{A}$, scale bar $=0.2 \mu \mathrm{m})$. SDC-I was detected by immunohistochemistry $(\mathbf{B}$, magnification, $\times 200 ;$ scale bar, $50 \mu \mathrm{m})$ and Western blot $(\mathbf{F})$. The MMP-9 was detected by immunofluorescence (D, magnification, $\times 200$; scale bar, $50 \mu \mathrm{m}$ ) and Western blot (G). The SDC-I in the BALF was measured by SDC-I ELISA $(\mathbf{E})$. (C, $\mathbf{H}$, and $\mathbf{I})$ protein intensity analysis of $(\mathbf{B}, \mathbf{F}$, and $\mathbf{G})$ respectively. (J) Fluorescence intensity analysis of $(\mathbf{D})$. All data are presented as the mean \pm SD of three independent experiments. ${ }^{\#} p<0.05$ vs the control group. 
lung tissue in the LPS group showed pulmonary interstitial hyperemia, edema, infiltration of inflammatory cytokine (TNF- $\alpha$, IL-1 $\beta$, and IL-6), and FITC-albumin. Over time, the pathological lesions of lung and FITC-albumin infiltration became severe after 6 hours of LPS treatment.

\section{Glycocalyx Shedding in Lungs Was the Highest After 6 Hours of LPS Treatment}

The electron microscope results (Figure 2A) showed that glycocalyx on the surface becomes significantly thinner after LPS stimulation. The highest severity was observed at the sixth hour of LPS stimulation and was slightly repaired after 12, 18, and 24 hours of LPS. The change in SDC-1, which is the main component of the glycocalyx, was further studied by immunohistochemistry and Western blot (Figure 2B, C, F and H). Similarly, SDC-1 shedding was the most severe after 6 hours of LPS stimulation. In addition, the highest severity of SDC-1 shedding in the
BALF was observed after 6 hours of LPS stimulation and was decreased after 12, 18, and 24 hours of LPS (Figure 2E).

The MMP-9 plays a major role in the degradation and shedding of SDC-1. Immunofluorescence results (Figure 2D, G, I and J) showed that MMP-9 was significantly expressed after LPS stimulation compared with the control group. The MMP-9 expression was the highest at the sixth hour of LPS stimulation (Figure 2D, G, I and J).

\section{Impairment of Tight Junction in Lungs Began to Worsen at $6 \mathrm{~h}$ of LPS Treatment} Tight junction function was evaluated by detecting occludin and ZO-1. The results (Figure $3 \mathrm{~A}-\mathrm{H}$ ) consistently showed that the expression levels of occludin and ZO-1 at the sixth hour of LPS treatment began to decrease. The results also indicated that the damage to tight junction in lungs was the most severe during the sixth hour of LPS stimulation (Figure $3 \mathrm{~A}-\mathrm{H}$ ).
A
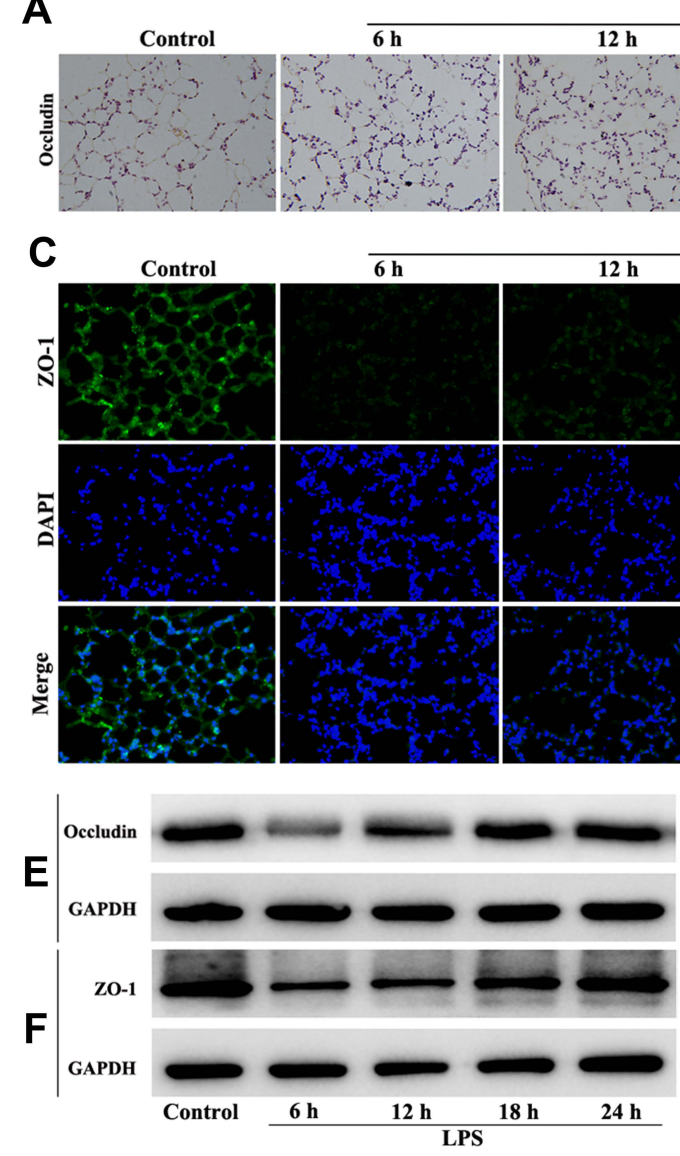

LPS

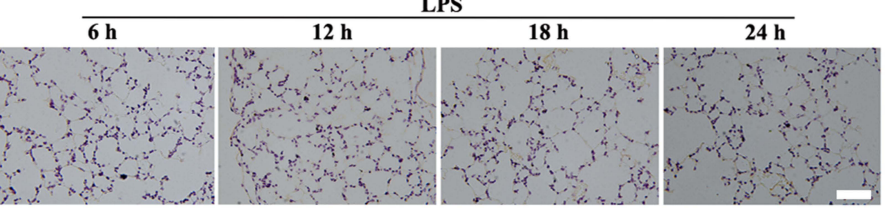

LPS
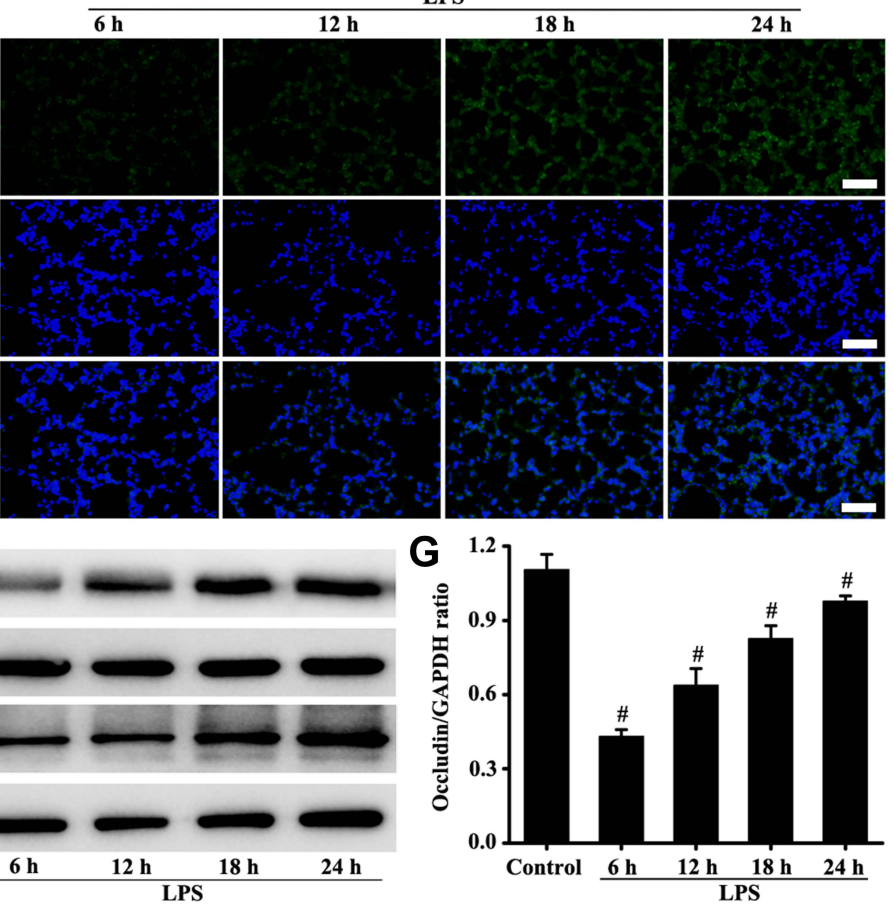
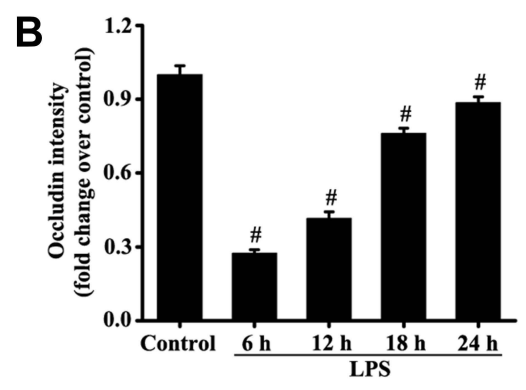

D

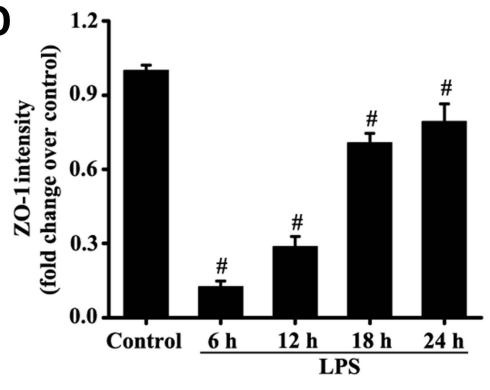

H

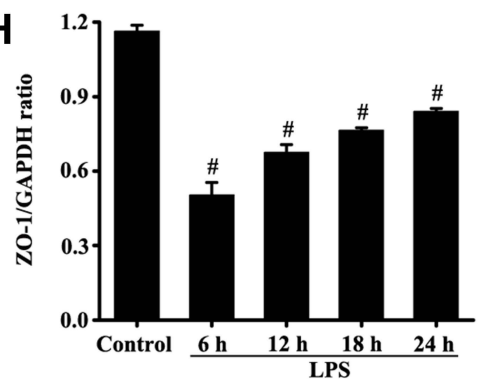

Figure 3 Mice were intratracheally atomized with $5 \mathrm{mg} / \mathrm{kg}$ LPS (stimulation for 6, 12, 18, and $24 \mathrm{~h}$ ) to observe the changes of tight junction. Occludin protein was detected by immunohistochemistry (A, magnification, $\times 200$; scale bar, $50 \mu \mathrm{m})$ and Western blot $(\mathbf{E})$. The ZO-I protein was detected by immunofluorescence technique $(\mathbf{C}$, magnification, $\times 200$; scale bar, $50 \mu \mathrm{m}$ ) and Western blot $(\mathbf{F})$. (D) Fluorescence intensity analysis of $(\mathbf{C})$. (B, $\mathbf{G}$, and $\mathbf{H})$ are the protein intensity analyses of $(\mathbf{A}$, $\mathbf{E}$ and $\mathbf{F})$ respectively. All data are presented as the mean \pm SD of three independent experiments. ${ }^{\#} p<0.05$ vs the control group. 


\section{Active MMP-9 Protein Led to SDC-I}

Shedding and Tight Junction Damage

\section{in vitro}

The results in Figure 4A, B, D-G showed that SDC-1, ZO-1, and occludin expression significantly decreased in active MMP-9 group compared with the control group. In addition, SDC-1 shedding of cell culture medium was increased in the active MMP-9 group (Figure 4C). The above results indicated that the active MMP-9 significantly worsened SDC-1 shedding and tight junction damage.

\section{Downregulation MMP-9 Expression Alleviated SDC-I Shedding in vitro and in vivo}

The results of in vivo experiments showed that the damage to the glycocalyx and tight junction in lungs of mice began to aggravate at the sixth hour of LPS treatment (Figures 2 and 3). To further clarify the relationship between the glycocalyx and junction, LPS stimulation at the sixth hour for relevant studies was selected.

The results in vitro and in vivo (Figure 5A-D) showed that LPS-induced MMP-9 expression significantly decreased by MMP-9 siRNA or MMP-9 shRNA compared with the control groups.

The results in vivo (Figure 6A-E and $\mathrm{G}$ ) showed that glycocalyx SDC-1 shedding and FITC-albumin infiltration significantly increased in the LPS group compared with the control and LV2-NC groups. However, glycocalyx SDC-1 shedding and FITC-albumin infiltration were inhibited by downregulation MMP-9 expression in the MMP-9 shRNA+LPS group (Figure 6A-E and G). In addition, glycocalyx SDC-1 shedding mediated by LPS was inhibited by downregulation MMP-9 expression in the MMP-9 siRNA+LPS group (Figure 6F, H and I).

The above results indicated that downregulation MMP-9 expression significantly alleviated LPS-induced SDC-1 shedding.
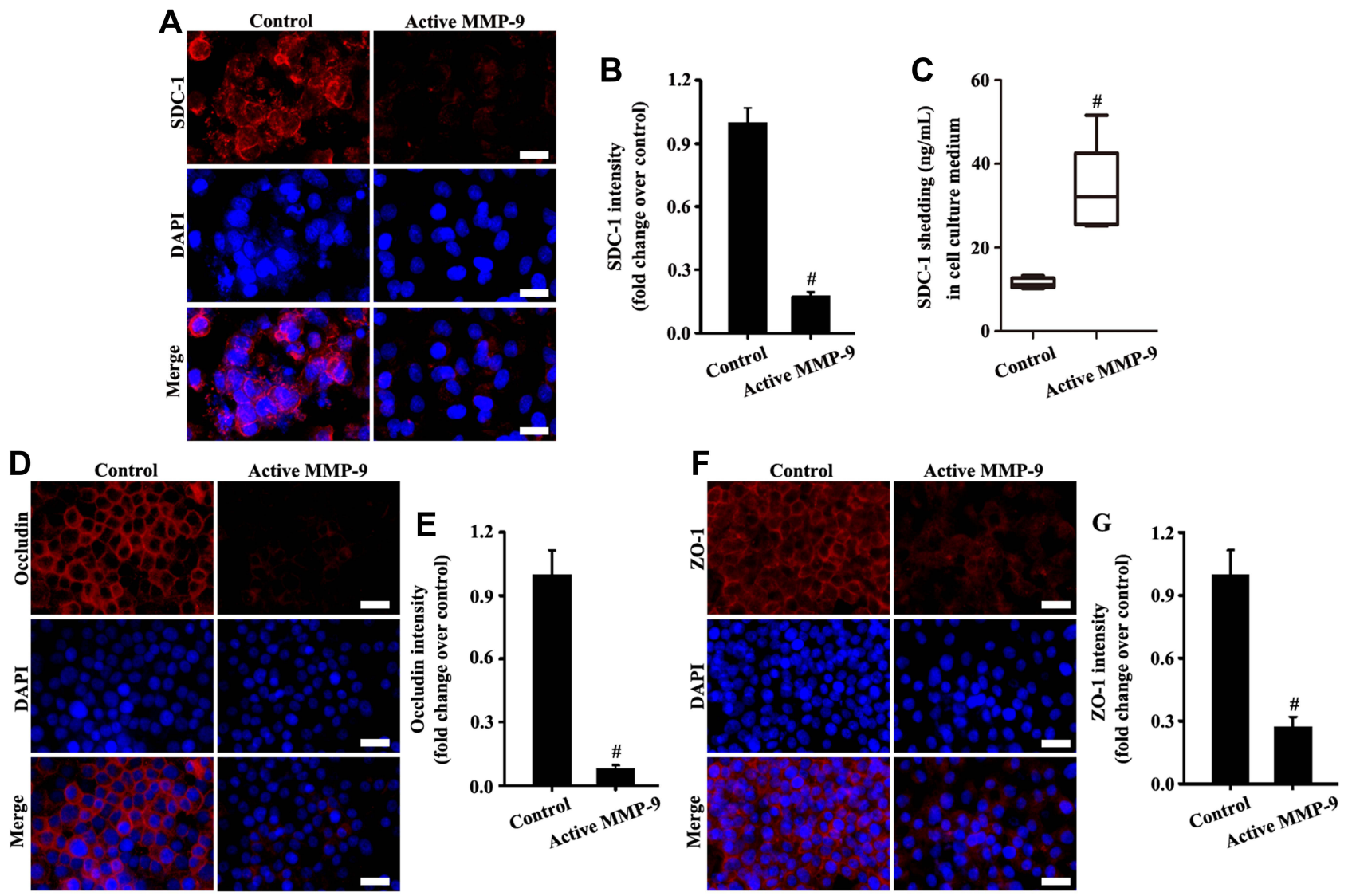

Figure 4 Active MMP-9 protein led to SDC-I shedding and tight junction damage. A549 cells were cultured with active human MMP-9 (0.8 $\mu$ g/mL) in the medium. SDC-I (A, magnification, $\times 200$; scale bar, $50 \mu \mathrm{m}$ ), occludin (D, magnification, $\times 200$; scale bar, $50 \mu \mathrm{m})$, and ZO-I (F, magnification, $\times 200$; scale bar, $50 \mu \mathrm{m})$ in A549 were detected by immunofluorescence. SDC-I shedding in the cell culture medium was measured by SDC-I ELISA (C). (B, E, and $\mathbf{G})$ are fluorescence intensity analyses of (A, D, and $\mathbf{F}$ ) respectively. All data are presented as the mean \pm SD of three independent experiments. ${ }^{\#} p<0.05$ vs the control group. 


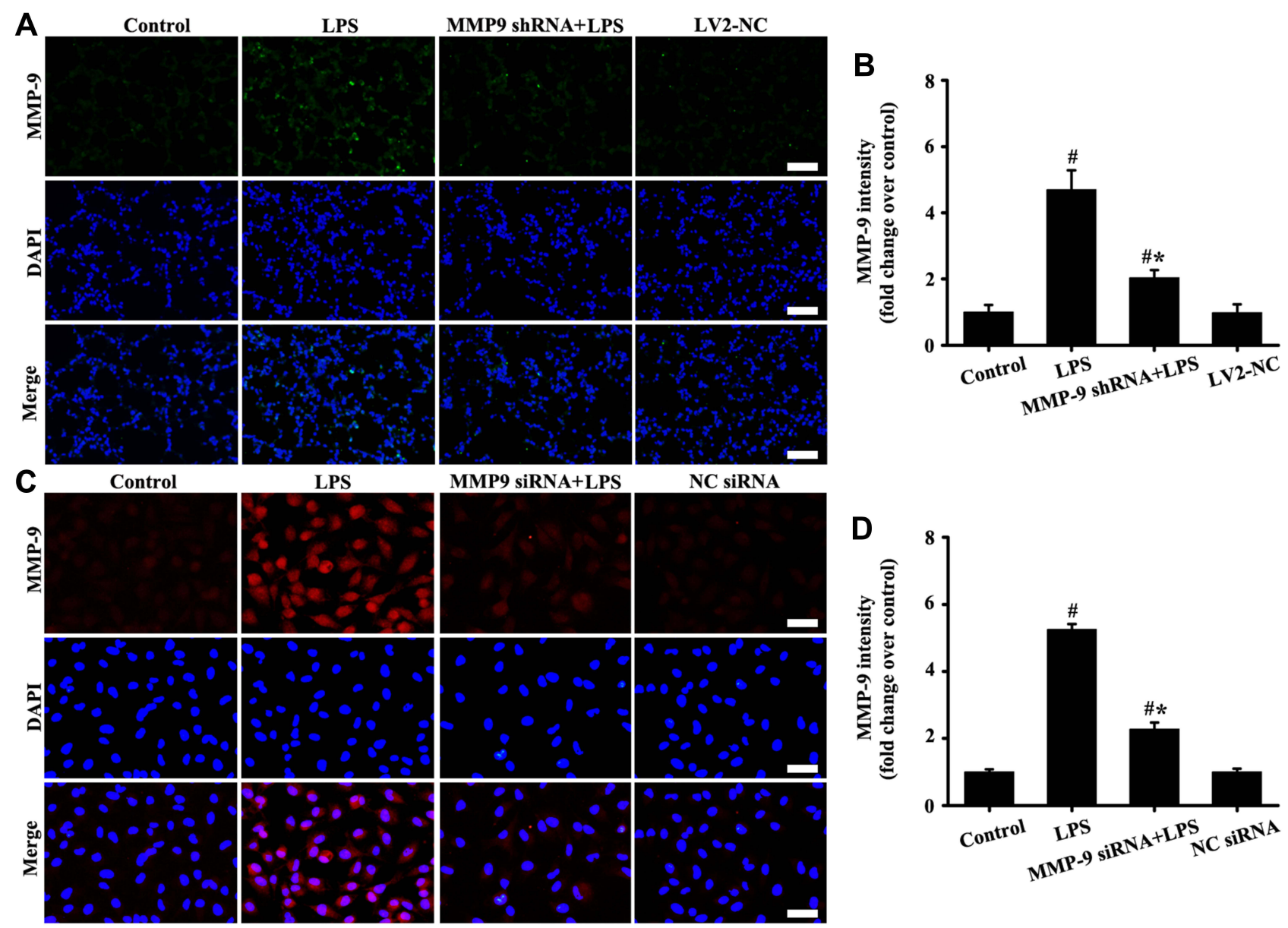

Figure 5 Downregulation MMP-9 expression in vivo and in vitro. The mice were injected by tail vein with a of total $2 U$ MMP-9 shRNA, and then exposed to LPS for stimulation of six hours LPS. The A549 cells were transfected with $40 \mathrm{nM} \mathrm{MMP-9}$ siRNA and Lipofectamine 2000 for 48 hours, and then added with LPS (I00 ng/mL) for stimulation of six hours. MMP-9 in vivo (A, magnification, $\times 200$; scale bar, $50 \mu \mathrm{m})$ and vitro (C, magnification, $\times 200$; scale bar, $50 \mu \mathrm{m})$ was detected by immunofluorescence. (B and $\mathbf{D})$ are fluorescence intensity analysis of $(\mathbf{A}$ and $\mathbf{C})$ respectively. All data are presented as the mean \pm SD of three independent experiments. ${ }^{\#} p<0.05$ vs the control group, ${ }^{*} p<0.05$ vs the LPS group.

\section{Downregulation MMP-9 Expression Alleviated Tight Junction Impairment in vivo and in vitro}

The in vivo (Figure 7A-D) and in vitro (Figure 7E-H) results showed that the expression levels of occludin and ZO-1 significantly decreased in the LPS group compared with those in the control group. However, down-regulation MMP-9 expression by MMP shRNA in vivo (Figure 7A-D) and MMP-9 siRNA in vitro (Figure 7E-H) significantly restored the expression of occludin and ZO-1. The above results indicated that down-regulation MMP-9 expression protected SC-1 from shedding, thereby alleviating tight junction damage.

\section{Recombinant Mouse SDC-I Protein Alleviated Glycocalyx Shedding and Tight Junction Damage in Mice}

The alveolar glycocalyx and tight junction structure of the lungs was intact in the control group (Figure 8A-E). However, results in the LPS groups showed that glycocalyx and tight junction structure were damaged by LPS stimulation (Figure 8A-E). In comparison with the LPS group, alveolar glycocalyx and tight junction structure damage of the lungs significantly decreased due to the pretreatment with recombinant mouse SDC-1 protein in the recombinant SDC-1+LPS group (Figure 8A-E). These data indicated that pretreatment with recombinant mouse SDC-1 protein significantly decreased tight junction structure damage in LPS-induced early ALI. 

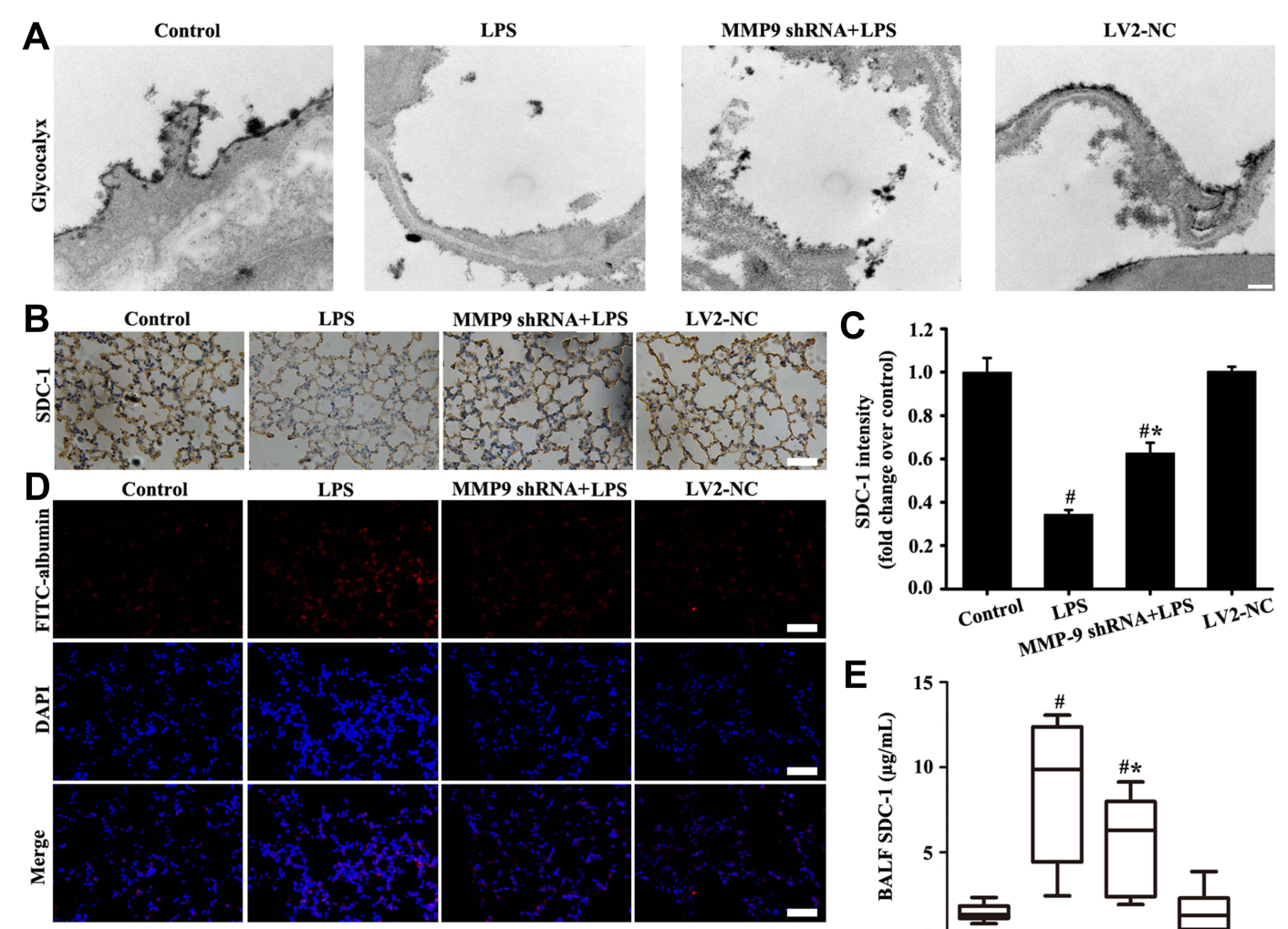

LPS

MMP9 ShRNA+LPS

LV2-NC

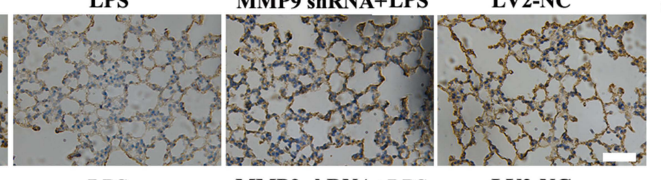

C $\begin{array}{rr}1.2 \\ \end{array}$

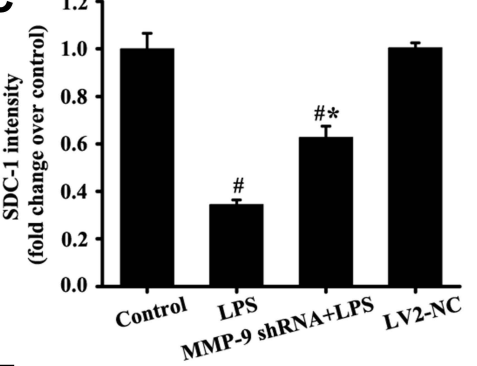

E

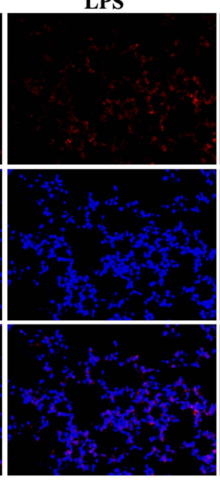

MMP9 shRNA+LPS

LV2-NC
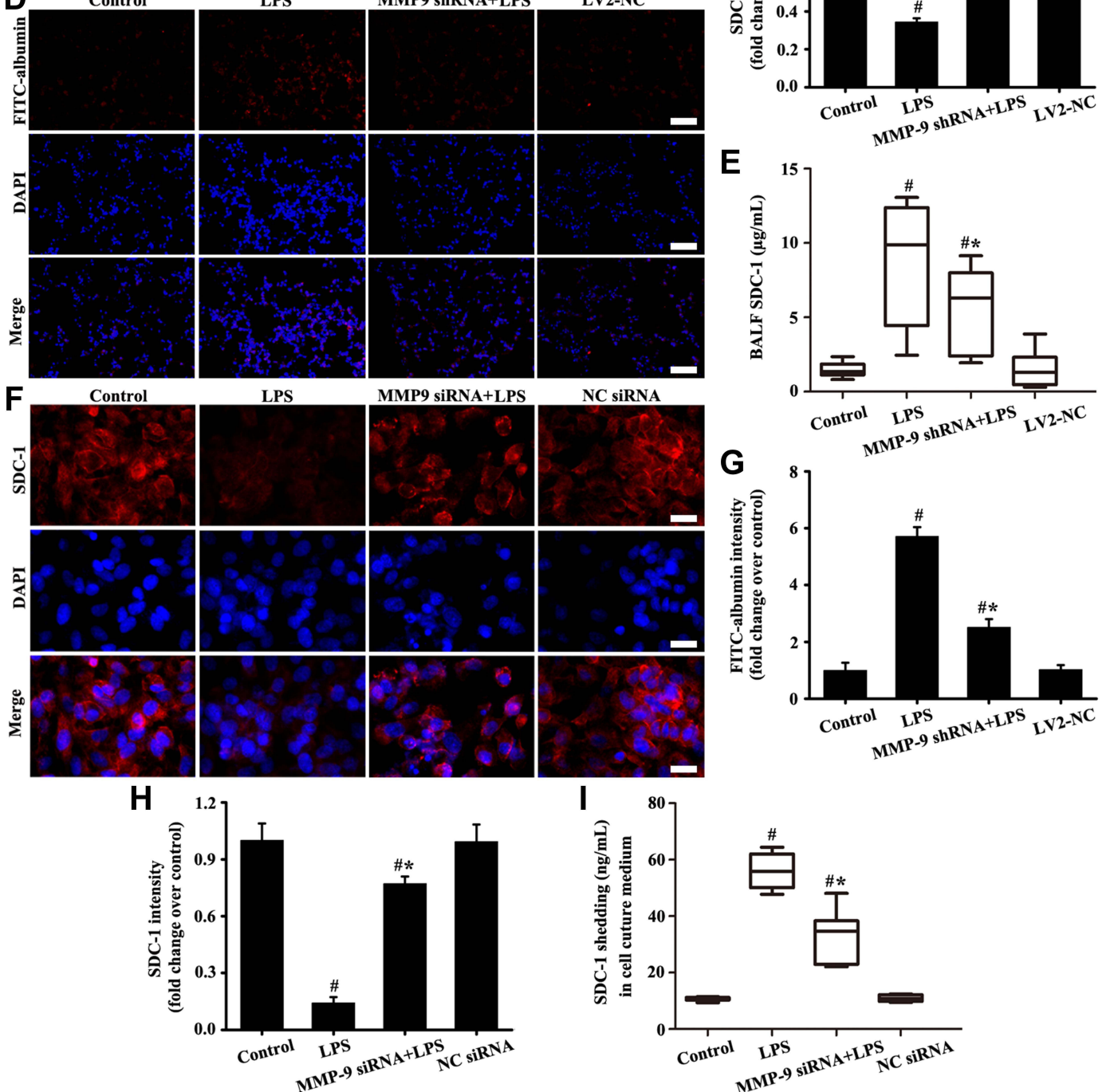

Figure 6 Downregulation MMP-9 expression alleviated SDC-I shedding in vitro and in vivo. Glycocalyx was conducted by an electron microscope $(\mathbf{A}:$ scale bar $=0.2 \mu \mathrm{m})$. SDC-I was detected by immunohistochemistry (B, magnification, $\times 200$; scale bar, $50 \mu \mathrm{m})$. FITC-albumin (D, magnification, $\times 200$; scale bar, $50 \mu \mathrm{m})$ in mice and SDC-I (F, magnification, $\times 200$; scale bar, $50 \mu \mathrm{m}$ ) in A549 cells were detected by immunofluorescence. The soluble SDC-I Levels in the BALF (E) and cell culture medium (I) was measured by SDC-I ELISA. (C) Protein intensity analysis of $(\mathbf{B})$. ( $\mathbf{G}$ and $\mathbf{H})$ are the fluorescence intensity analysis of $(\mathbf{D}$ and $\mathbf{F})$ respectively. All data are presented as the mean \pm SD of three independent experiments. ${ }^{\#}<0.05$ vs the control group, ${ }^{\# *} p<0.05$ vs the LPS group. 


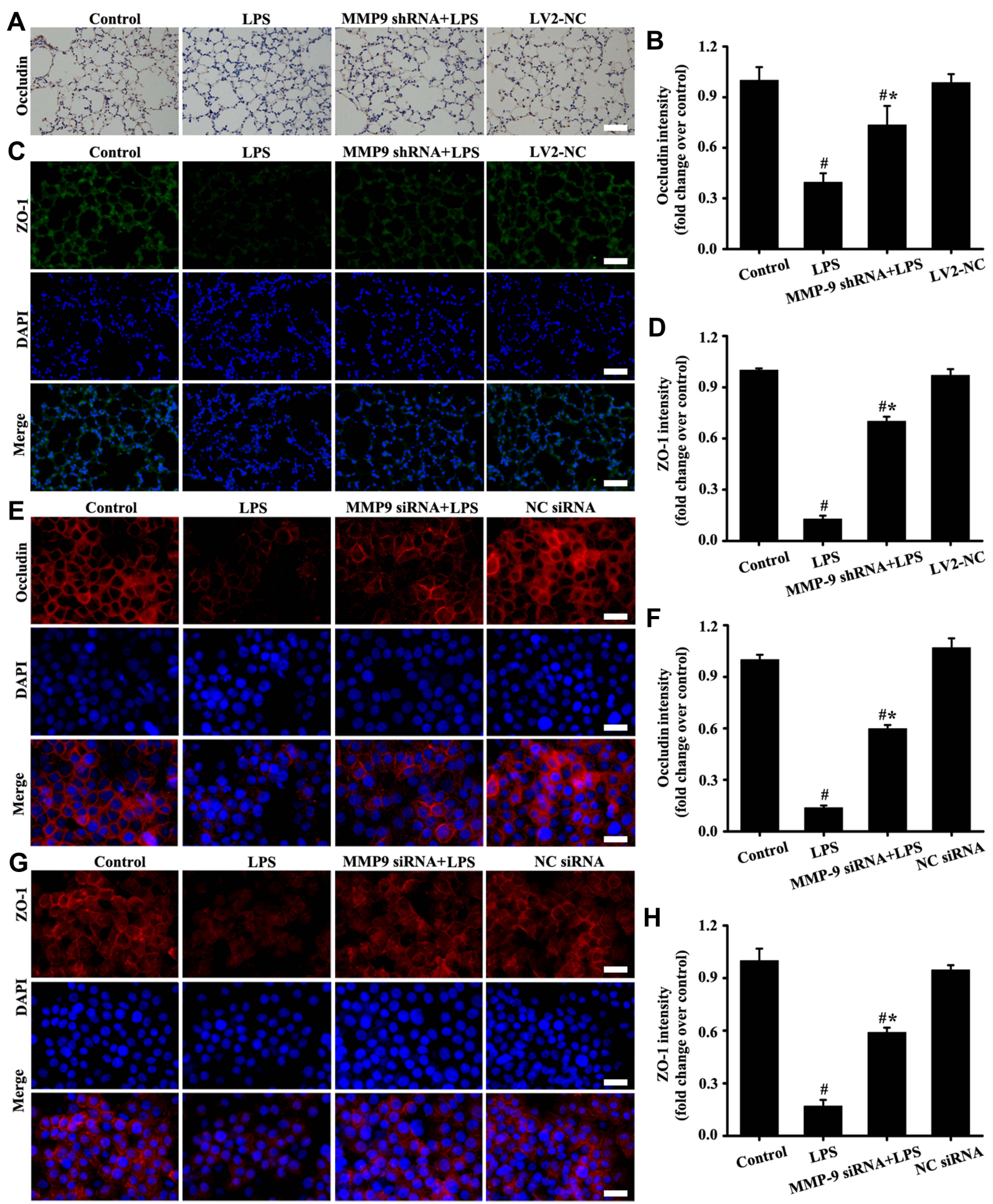

Figure 7 Downregulation MMP-9 expression alleviated tight junction impairment in vivo and in vitro. Occludin was detected by immunohistochemistry (A, magnification, $\times 200$; scale bar, $50 \mu \mathrm{m})$ and immunofluorescence $(\mathbf{E}$, magnification, $\times 200$; scale bar, $50 \mu \mathrm{m})$. The ZO-I in mice $(\mathbf{C}$, magnification, $\times 200$; scale bar, $50 \mu \mathrm{m})$ and $\mathbf{A} 549$ cells $(\mathbf{G}$, magnification, $\times 200$; scale bar, $50 \mu \mathrm{m})$ were detected by immunofluorescence. (B) is the protein intensity analysis of $(\mathbf{A})$. (D, F, and $\mathbf{H})$ are the fluorescence intensity analyses of $(\mathbf{C}, \mathbf{E}$ and $\mathbf{G})$ respectively. All data are presented as the mean \pm SD of three independent experiments. ${ }^{\#} p<0.05$ vs the control group, ${ }^{*} * p<0.05$ vs the LPS group. 


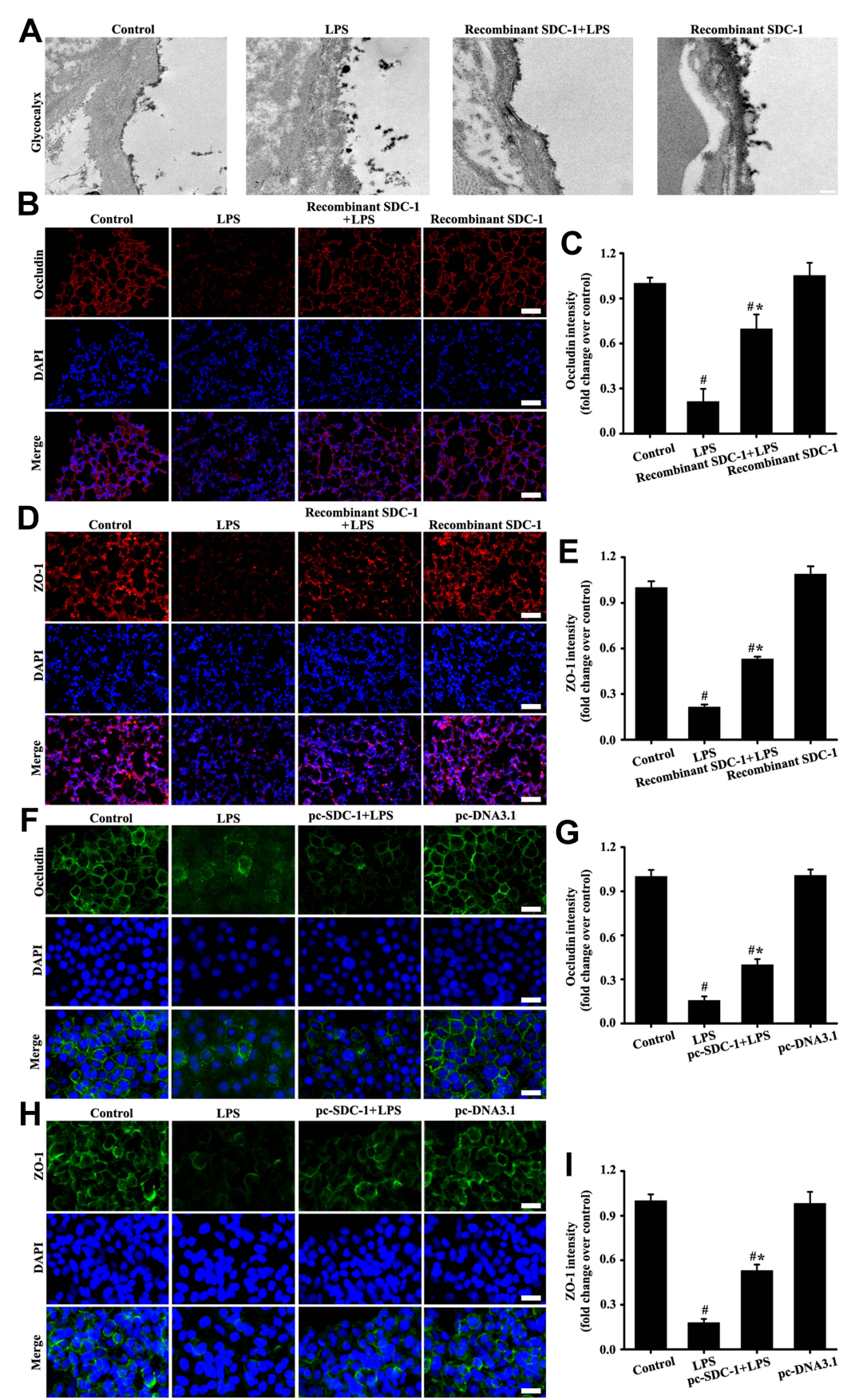

Figure 8 Recombinant mouse SDC-I protein alleviated glycocalyx shedding and tight junction damage in mice, and overexpression SDC-I alleviated tight junction damage in A549 cells. The mice were intratracheally atomized with $500 \mathrm{ng} /$ day recombinant SDC-I protein for 7 days and then exposed to LPS to stimulate for six hours. The lipofectamine 3000 reagent and pc-SDC-I (I $\mu \mathrm{g} / \mathrm{mL})$ were employed for A549 cells transfection. Forty-eight hours after transfection, the A549 cells were cultured with LPS $(100 \mathrm{ng} / \mathrm{mL})$ stimulation for six hours. Glycocalyx was conducted by an electron microscope (A: scale bar $=0.2 \mu \mathrm{m})$. Occludin in mice $(\mathbf{B}$, magnification, $\times 200 ;$ scale bar, 50 $\mu \mathrm{m})$ and A549 cells (F, magnification, $\times 200$; scale bar, $50 \mu \mathrm{m}$ ) were detected by immunofluorescence. The ZO-I in mice (D, magnification, $\times 200 ;$ scale bar, $50 \mu \mathrm{m})$ and A549 cells $(\mathbf{H}$, magnification, $\times 200$; scale bar, $50 \mu \mathrm{m})$ were detected by immunofluorescence. $(\mathbf{C}, \mathbf{E}, \mathbf{G}$, and $\mathbf{I})$ are the fluorescence intensity analyses of $(\mathbf{B}, \mathbf{D}, \mathbf{F}$ and $\mathbf{H})$ respectively. All data are presented as the mean \pm SD of three independent experiments. ${ }^{\#}<0.05$ vs the control group, ${ }^{\# *} p<0.05$ vs the LPS group.

\section{Overexpression SDC-I Alleviated Tight Junction Damage in A549 Cells}

The in vitro (Figure 8F-I) results showed that tight junction damage significantly decreased in the LPS groups compared with those in the control and pc-
DNA3.1 groups. However, up-regulation expression by pc-SDC-1 in vivo (Figure $8 \mathrm{~F}-\mathrm{I}$ ) significantly restored occludin and ZO-1 expression. The above results indicated that up-regulation SDC-1 expression protected from tight junction damage. 

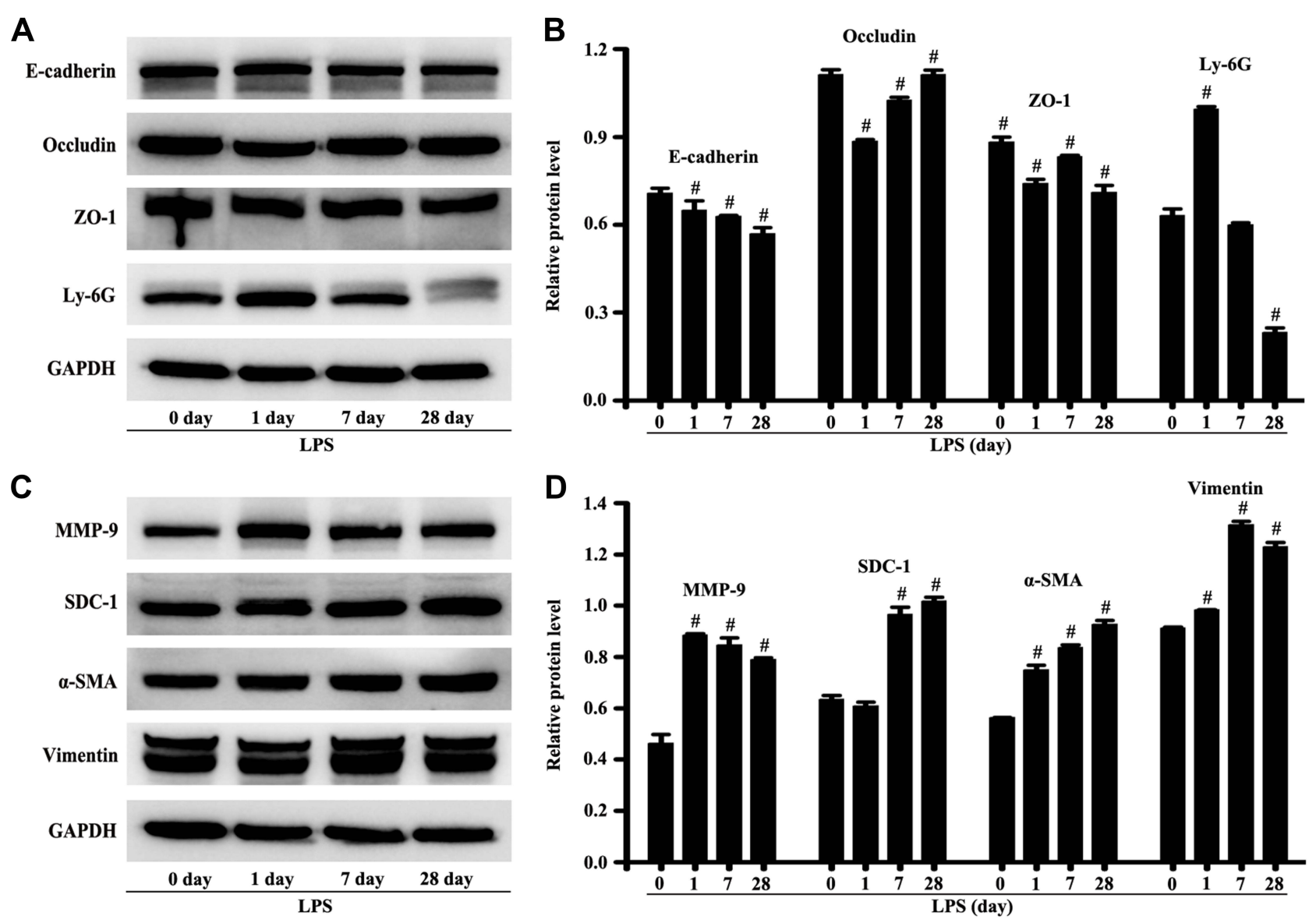

Figure 9 SDC-I shedding without early intervention might develop into pulmonary fibrosis. The mice were intratracheally atomized with 5 mg/kg LPS to stimulate for 28 days. The proteins of e-cadherin, occludin, ZO-I, Ly-6G, MMP-9, SDC-I, a-SMA, vimentin, and GAPDH were detected by the Western blot (A and C). The GAPDH was used as internal control. (B and $\mathbf{D})$ are protein intensity analyses of $(\mathbf{A}$ and $\mathbf{C})$ respectively. All data are presented as the mean \pm SD of three independent experiments. ${ }^{\#} p<0.05$ vs the control group.

\section{SDC-I Shedding without Early Intervention Might Develop into Pulmonary Fibrosis}

The mice were stimulated by LPS for 28 days to observe the self-repair of lung injury. The protein expression of vimentin, $\alpha$-SMA, MMP-9, and SDC-1 in lung tissue significantly increased compared with the control group, while SDC-1 did not renovate the damage to occludin, e-cadherin, and ZO-1 in mice stimulated by LPS for 28th day (Figure 9A-D). In addition, the neutrophil protein expression of Ly-6G in the lung tissue significantly decreased compared with the control group (Figure 9A-D). Therefore, SDC-1 shedding in LPSinduced early ALI may lead to pulmonary fibrosis without early intervention.

\section{Discussion}

The structural damage to epithelial cells is the main pathological feature of ALI. In recent years, epithelial glycocalyx shedding and junction injury are considered key factors to pulmonary physical barrier. ${ }^{19,20}$ In the present study, changes in the epithelial glycocalyx and tight junction were dynamically observed in early ALI induced by LPS. The present study demonstrated that protection SDC-1 shedding by inhibiting the MMP-9 can significantly alleviate damage to tight junction, hence reducing pulmonary edema in LPS-induced early ALI (Figure 10).

SDC-1 in the glycocalyx plays an important role in response to ischemia-reperfusion injury, hyperglycemia, endotoxemia, septic shock, and abnormal blood shear stress. $^{21-24}$ Chen et al also showed that pretreatment with $\mathrm{NAH}$ protects HS shedding from the intestinal mucosal surfaces in cecal ligation and perforation-induced mouse septic intestinal injury. ${ }^{25}$ The results in the present study showed that downregulation of MMP-9 is significantly protected against LPS-induced SDC-1 shedding, thereby reducing the damage to tight junction. In addition, Tanyalak et al revealed that SDC-1 promotes lung fibrosis 


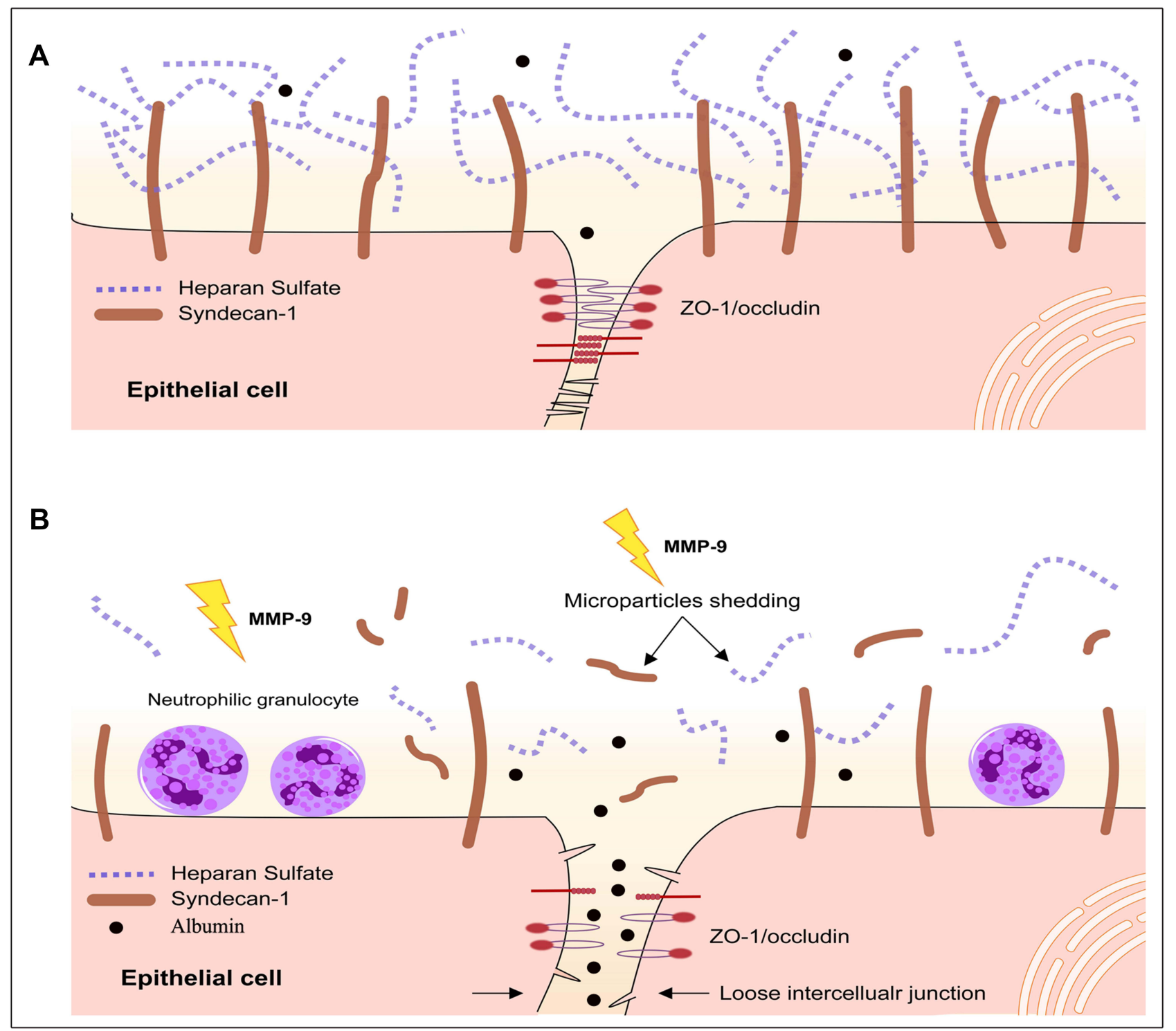

Figure 10 Structure of epithelial glycocalyx and tight junction. Epithelium was covered with a layer of glycocalyx, whose main component is SDC-I (A). Tight junction proteins consist of the integral transmembrane protein occludin and intracellular protein ZO-I and other accessory proteins (A). The ZO-I binds to the cytoplasm of occludin. When the structures of the glycocalyx and tight junction proteins were damaged, albumin leakage occurred (B).

by regulating epithelial reprogramming through extracellular vesicles in the lungs of patients with IPF and in murine models after bleomycin injury. ${ }^{8}$ Lan et al also testified that the glycocalyx, especially HS, from fibrotic lungs induced by a single injection of bleomycin is significantly under sulfated up to 30 days. $^{26}$ The present results show that the levels of SDC-1, $\alpha$-SMA, and vimentin were significantly elevated after LPS stimulation for 28 days, thus SDC-1 in the glycocalyx may be another class of signaling molecules involved to promote the development of pulmonary fibrosis from LPS-induced late lung injury.
The MMP-9, a member of the MMP family, is involved in the degradation and shedding of SDC- 1 and related to the migration of neutrophils. ${ }^{27}$ Notably, MMP-9 participates in airway remodeling by promoting extracellular matrix deposition and the proliferation and migration of airway smooth muscle cells in the lung airway remodeling disease. ${ }^{28,29}$ During the dynamic observation of the repair process of lung injury, the levels of MMP-9 and the fibrosis indicators, namely, $\alpha$-SMA and vimentin were significantly elevated after LPS stimulation for 28 days. These results suggested that MMP-9 might promote the development of pulmonary fibrosis from early lung injury. 
Tight junction plays a major role in regulating and guaranteeing the integrity of pulmonary blood and gas barrier. Tight junction proteins are mainly composed of occludin, $\mathrm{ZO}-1, \mathrm{ZO}-2$, and ZO-3. ${ }^{30}$ Occludin is a transmembrane integrin that forms a tight junction between cells. ZO-1 is an intracellular protein that binds with the cytoplasm of occludin and locates occludin in the cytoskeleton to ensure the integrity of tight junction. ${ }^{31}$ Based on a previous study, ${ }^{13}$ inhibiting SDC-1 shedding signaling may be a useful therapeutic against tight junction damage. The present study also demonstrated that the protection of the glycocalyx significantly alleviated the tight junction damage in LPS induced early ALI.

Adherens junction protein called e-cadherin is also involved in epithelial barrier function, thereby regulating migration and mediating the spread of proinflammatory responses. ${ }^{32,33}$ Nagasawa et al showed that the gap junction protein connexin 43 (CX43) was closely associated with tight junction proteins of the brain and lung endothelial cells. ${ }^{34}$ Mensah et al demonstrated that HS degradation disrupts endothelial cell gap junction protein $\mathrm{Cx} 43 .{ }^{13}$ These studies revealed a close relationship between the glycocalyx SDC-1 and tight junction in the LPS-induced early ALI. Therefore, exploring the relationship between SDC-1 and adhesion junctions is necessary in future studies.

This study has certain limitations. On the one hand, the effect of SDC-1 on tight and adherens junction at the cellular and mouse levels was studied, and not in higher animals. On the other hand, whether other signaling pathways involving SDC-1 affect pulmonary fibrosis induced by LPS needed further study.

In conclusion, this study showed that protection SDC-1 shedding significantly inhibited tight junction damage and reduced pulmonary injury. More importantly, this study also revealed that SDC-1 may promote the transition from acute lung injury induced by LPS to pulmonary fibrosis.

\section{Conclusion}

Therefore, our study demonstrated that glycocalyx SDC-1 shedding mediated by MMP-9 can significantly aggravate tight junction damage, which further increased the pulmonary edema. These results also suggested that glycocalyx SDC-1 may be a promising therapeutic target for treating pulmonary edema with ALI.

\section{Acknowledgments}

The work was funded by the National Natural Science Foundation of China (81770029).

\section{Disclosure}

The authors report no conflicts of interest in this work.

\section{References}

1. Gotts JE, Abbott J, Fang X, et al. Cigarette smoke exposure worsens endotoxin-induced lung injury and pulmonary edema in mice. Nicotine Tob Res. 2017;19:1033-1039. doi:10.1093/ntr/ntx062

2. Ahn D, Prince A. Participation of the IL-10RB related cytokines, IL22 and IFN- $\lambda$ in defense of the airway mucosal barrier. Front Cell Infect Microbiol. 2020;10:300. doi:10.3389/fcimb.2020.00300

3. Croasdell LA, Gachanja NN, Rossi AG, et al. Epithelial cells and inflammation in pulmonary wound repair. Cells. 2021;10:339. doi:10.3390/cells10020339

4. Ochs M, Hegermann J, Lopez-Rodriguez E, et al. On top of the alveolar epithelium: surfactant and the glycocalyx. Int $\mathrm{J} \mathrm{Mol} \mathrm{Sci.}$ 2020;21:3075. doi:10.3390/ijms21093075

5. Zhang D, Qi BY, Zhu WW, et al. Crocin alleviates lipopolysaccharide-induced acute respiratory distress syndrome by protecting against glycocalyx damage and suppressing inflammatory signaling pathways. Inflamm Res. 2020;69:267-278. doi:10.1007/ s00011-019-01314-z

6. Brandt R, Timm S, Gorenflos LJL, et al. Metabolic glycoengineering enables the ultrastructural visualization of sialic acids in the glycocalyx of the alveolar epithelial cell line hAELVi. Front Bioeng Biotechnol. 2021;8:614357. doi:10.3389/fbioe.2020.614357

7. Clark RL. Genesis of placental sequestration in malaria and possible targets for drugs for placental malaria. Birth Defects Res. 2019;111:569-583. doi:10.1002/bdr2.1496

8. Tanyalak P, Changfu Y, David MH, et al. Syndecan-1 promotes lung fibrosis by regulating epithelial reprogramming through extracellular vesicles. JCI Insight. 2019;5:e129359.

9. Shin HE, Kwak SE, Zhang DD, et al. Effects of treadmill exercise on the regulation of tight junction proteins in aged mice. Exp Gerontol. 2020;141:111077. doi:10.1016/j.exger.2020.111077

10. Li X, Jamal M, Guo P, et al. Irisin alleviates pulmonary epithelial barrier dysfunction in sepsis-induced acute lung injury via activation of AMPK/SIRT1 pathways. Biomed Pharmacother. 2019;118:109363. doi:10.1016/j.biopha.2019.109363

11. Zhou J, Fu Y, Liu K, et al. MiR-206 regulates alveolar type II epithelial cell $\mathrm{Cx} 43$ expression in sepsis-induced acute lung injury. Exp Ther Med. 2019;18:296-304.

12. Li J, Wang K, Huang B, et al. The receptor for advanced glycation end products mediates dysfunction of airway epithelial barrier in a lipopolysaccharides-induced murine acute lung injury model. Int Immunopharmacol. 2021;93:107419. doi:10.1016/j.intimp.2021. 107419

13. Mensah SA, Cheng MJ, Homayoni H, et al. Regeneration of glycocalyx by heparan sulfate and sphingosine 1-phosphate restores inter-endothelial communication. PLoS One. 2017;12:e0186116. doi:10.1371/journal.pone.0186116

14. Chen WY, Huang YC, Yang ML, et al. Protective effect of rutin on LPS-induced acute lung injury via down-regulation of MIP-2 expression and MMP-9 activation through inhibition of Akt phosphorylation. Int Immunopharmacol. 2014;22:409-413. doi:10.1016/j.intimp.2014.07.026

15. Liu B, Cheng Y, Wu Y, et al. Emodin improves alveolar hypercoagulation and inhibits pulmonary inflammation in LPS-provoked ARDS in mice via NF-kappaB inactivation. Int Immunopharmacol. 2020;88:107020. doi:10.1016/j.intimp.2020.107020 
16. Huang JH, Li L, Yuan WF, et al. NEMO-binding domain peptide attenuates lipopolysaccharide-induced acute lung injury by inhibiting the NF- $\kappa \mathrm{B}$ signaling pathway. Mediators Inflamm. 2016;2016:7349603. doi:10.1155/2016/7349603

17. Cao Y, Liu Y, Ping F, et al. miR-200b/c attenuates lipopolysaccharide-induced early pulmonary fibrosis by targeting ZEB1/2 via p38 MAPK and TGF- $\beta / \operatorname{smad} 3$ signaling pathways. Lab Invest. 2018;98 (3):339-359. doi:10.1038/labinvest.2017.123

18. Suzuki K, Okada H, Takemura G, et al. Recombinant thrombomodulin protects against LPS-induced acute respiratory distress syndrome via preservation of pulmonary endothelial glycocalyx. $\mathrm{Br}$ J Pharmacol. 2020;177:4021-4033. doi:10.1111/bph.15153

19. Weidenfeld S, Kuebler WM. Shedding first light on the alveolar epithelial glycocalyx. Am J Respir Cell Mol Biol. 2018;59:283-284. doi:10.1165/rcmb.2018-0108ED

20. Zou J, Li Y, Yu J, et al. Idiopathic pulmonary fibrosis is associated with tight junction protein alterations. Biochim Biophys Acta Biomembr. 2020;1862:183205. doi:10.1016/j.bbamem.2020.183205

21. Jiang W, Wang X, Geng X, et al. Novel predictive biomarkers for acute injury superimposed on chronic kidney disease. Nefrologia. 2020;41:165-173. doi:10.1016/j.nefro.2020.06.007

22. Hirota T, Levy JH, Iba T. The influence of hyperglycemia on neutrophil extracellular trap formation and endothelial glycocalyx damage in a mouse model of type 2 diabetes. Microcirculation. 2020;2:e12617.

23. Goligorsky MS, Sun D. Glycocalyx in endotoxemia and sepsis. Am J Pathol. 2020;190:791-798. doi:10.1016/j.ajpath.2019.06.017

24. Psefteli PM, Kitscha P, Vizcay G, et al. Glycocalyx sialic acids regulate Nrf2-mediated signaling by fluid shear stress in human endothelial cells. Redox Biol. 2021;38:101816. doi:10.1016/j. redox.2020.101816

25. Chen S, He Y, Hu Z, et al. Heparanase mediates intestinal inflammation and injury in a mouse model of sepsis. J Histochem Cytochem. 2017;65(4):241-249. doi:10.1369/0022155417692536

26. Lan Y, Liu Y, He Y, et al. A single injection of bleomycin reduces glycosaminoglycan sulfation up to 30 days in the C57BL/6 mouse model of lung fibrosis. Int J Biol Macromol. 2020;160:319-327. doi:10.1016/j.ijbiomac.2020.05.087
27. Lingwal N, Padmasekar M, Samikannu B, et al. Inhibition of gelatinase B (matrix metalloprotease-9) activity reduces cellular inflammation and restores function of transplanted pancreatic islets. Diabetes. 2012;61:2045-2053. doi:10.2337/db11-1143

28. Oh CK, Ariue B, Alban RF, et al. PAI-1 promotes extracellular matrix deposition in the airways of a murine asthma model. Biochem Biophys Res Commun. 2002;294:1155-1160. doi:10.1016/ S0006-291X(02)00577-6

29. Wang Z, Li R, Zhong R. Extracellular matrix promotes proliferation, migration and adhesion of airway smooth muscle cells in a rat model of chronic obstructive pulmonary disease via upregulation of the PI3K/AKT signaling pathway. Mol Med Rep. 2018;18:3143-3152.

30. Inoko A, Itoh M, Tamura A, et al. Expression and distribution of ZO-3, a tight junction MAGUK protein, in mouse tissues. Genes Cells. 2003;8:837-845. doi:10.1046/j.1365-2443.2003.00681.x

31. Fanning AS, Jameson BJ, Jesaitis LA, et al. The tight junction protein ZO-1 establishes a link between the transmembrane protein occludin and the actin cytoskeleton. J Biol Chem. 1998;273:9745-29753. doi:10.1074/jbc.273.45.29745

32. Huang S, Sun Y. Long noncoding RNA MNX1-AS1 functions as a competing endogenous RNA to regulate epithelial-mesenchymal transition by sponging MiR-744-5p in colorectal cancer. Biosci Biotechnol Biochem. 2021;85:568-578. doi:10.1093/bbb/zbaa096

33. Lu J, Liu D, Tan Y, et al. M1 Macrophage exosomes MiR-21a-5p aggravates inflammatory bowel disease through decreasing e-cadherin and subsequent ILC2 activation. J Cell Mol Med. 2021;25:3041-3050. doi:10.1111/jcmm. 16348

34. Nagasawa K, Chiba H, Fujita H, et al. Possible involvement of gap junctions in the barrier function of tight junctions of brain and lung endothelial cells. J Cell Physiol. 2006;208:123-132. doi:10.1002/ jcp. 20647
Journal of Inflammation Research

\section{Publish your work in this journal}

The Journal of Inflammation Research is an international, peerreviewed open-access journal that welcomes laboratory and clinical findings on the molecular basis, cell biology and pharmacology of inflammation including original research, reviews, symposium reports, hypothesis formation and commentaries on: acute/chronic inflammation; mediators of inflammation; cellular processes; molecular

\section{Dovepress}

mechanisms; pharmacology and novel anti-inflammatory drugs; clinical conditions involving inflammation. The manuscript management system is completely online and includes a very quick and fair peerreview system. Visit http://www.dovepress.com/testimonials.php to read real quotes from published authors. 